\title{
Identification of Issues Encountered by Students in Completing Their Research Dissertations for the Master of Education Degree Programme
}

\author{
W. M. Shaminda Wanasinghe \\ Department of Secondary \& Tertiary Education, Faculty of Education, The Open University of Sri Lanka, Nawala, Sri Lanka \\ Email: wmwan@ou.ac.lk
}

How to cite this paper: Shaminda Wanasinghe, W. M. (2020). Identification of Issues Encountered by Students in Completing Their Research Dissertations for the Master of Education Degree Programme. Open Journal of Social Sciences, 8, 36-44. https://doi.org/10.4236/jss.2020.812004

Received: October 27, 2020

Accepted: December 6, 2020

Published: December 9, 2020

Copyright $\odot 2020$ by author(s) and Scientific Research Publishing Inc. This work is licensed under the Creative Commons Attribution International License (CC BY 4.0).

http://creativecommons.org/licenses/by/4.0/

(c) (i) Open Access

\begin{abstract}
Conducting educational research is important as it aims at providing reliable information regarding educational problems which lead to the recommendation of informed solutions to those problems. Educational research can be defined as a "purposeful and systematic" enquiry "to solve a problem, illuminate a situation or add to our knowledge" (Forbes, 2015). Therefore, the research component is a vital part of the Master of Education post graduate degree conducted by the Faculty of Education, at the Open University of Sri Lanka. Our experience as members of the faculty is that the students, who have the potential to work as prospective researchers in the field of education, find it difficult to complete the research dissertation due to a variety of reasons. Therefore, the objectives of this study were to identify academic issues faced by the students in conducting research for the Masters' Degree, to identify personal issues faced by the students which affect the completion of their research as well as to make suggestions to overcome the issues faced by them in conducting their research. The survey method was used as a research methodology to achieve these objectives. Data collection was done by using a questionnaire handed to the students reading for the degree programme. A sample of 176 students who were in the second year of Master of Education Degree programme was the informants of the study. Data derived using the survey questionnaire was analysed both quantitatively and qualitatively. According to the findings, issues on the identification of a proper area of research, insufficiency of relevant literature and other related information on the proposed research study, unavailability of primary sources of data and research literature, lack of library facilities, the protracted time taken by the research supervisors to provide feedback, the difficulty of collecting data from
\end{abstract}


several samples, the complexity of completing an action research and not being interested in the selected research topic were identified as some of the academic issues encountered by the students. In conclusion, the study revealed that $24 \%$ of the samples encounter the issue of unavailability of primary sources of literature to conduct a review of literature. In addition, 36\% of students have issues connected with meeting supervisors. Workplace commitments, family commitments, health problems, insufficient support from family, problems on time management and having to travel long distances to university were also identified as personal issues. Preparing an action plan to meet the supervisors, conducting workshops for supervisors, preparing a checklist and comprehensive guidelines on writing and submission of the dissertation, maintaining a good rapport between the supervisor and student for sustaining their motivation are some of the methods recommended to overcome the issues encountered by the students during the period they conduct research for this degree programme.

\section{Keywords}

Issues, Research Study, Master of Education Degree Programme

\section{Introduction}

Conducting research is an important activity not just in the field of education but in any field of study. It primarily focuses on improving quality and is a search for knowledge. Educational research is important as it is conducted in order to provide reliable information regarding educational problems and their solutions. This type of research can be defined as a "purposeful and systematic" inquiry "to solve a problem, illuminate a situation or add to our knowledge" (Forbes, 2015). The need for educational research activities becomes imperative, and supports education to achieve its goals and objectives, rebuild confidence in public schools, adapt to cultural diversity, educate for self-identity and individual realization, re-establish faith in human, moral and democratic values, bring about changes in racial attitudes, achieve the goals of quality and relevance, and meet the challenges of the future world of accelerating scientific and technological change (Boykin, 1972). Therefore, educators can use research findings in the discipline of education to generate knowledge on the field of education, to improve the quality of educational practices and inform policy makers in the field of education. As such, it is important to motivate prospective researchers to engage in studies in the field of education. However, our experience as facilitators of postgraduate students in the discipline of education is that their completion of formal studies is hampered by their inability to complete their research. This situation reflects issues related to the low completion rate of such degree programmes and also issues pertaining to the need to find strategies to motivate prospective researchers in the field of education. The main objectives of this 
study were to identify academic issues and personal issues by the students conducting research for their Master Degree. The survey method was used as a research methodology to achieve those objectives. Data collection was done by using a questionnaire, a sample of 176 students who were in the second year of Master of Education Degree programme. The main reason for choosing this study was that the majority failed to submit the research dissertation on time. Therefore, students and supervisors can assist in minimizing the problems they face by identifying them. It is also possible to use these findings for future planning in this degree programme.

\section{Literature Review}

Graduate education entails an extensive learning process where students must follow tough courses, conduct research and write a dissertation (Akyürek \& Afacan, 2018). Conducting a research study is a challenging task where students have to acquire in-depth knowledge in the related field and plan the study according to a suitable research design (Qasem \& Zayid, 2019). The final output of the research study is expected to reflect the originality of the work done, critical and independent thinking and include thorough documentation and a well-prepared structure (Matin \& Khan, 2017). Successful completion of a postgraduate dissertation is influenced by different factors. These include factors related to the student (such as personal issues and level of academic competency) and the institution.

The personal life of a postgraduate student has a strong impact on his/her ability to complete a research dissertation with success. Issues related to personal relationships, family responsibilities, financial state, work and health can have a substantial impact in this regard; in addition, reduced interest in the selected research topic and changes in a career path also have a noteworthy impact (Wright, 2003). Other student-related factors that affect completion of research dissertations include the level of students' knowledge, prior experience, commitment, socio-economic conditions, communication skills and the ability for stress management and time management (Bocar, 2013).

Within a master's level education programme, students may also encounter different academic issues such as intrusive supervisors, difficulty in determining a research problem and topic as well as difficulties in obtaining legal permission to conduct the study (Alam, 2013). According to a study conducted in Turkey, the completion of students' dissertations is affected by issues related to research methodology (such as determining the research design, formulating data collection tools, conducting data analysis, and other issues related to the research process) and their level of knowledge (lessons remain theoretical, the course has insufficient content and research stage) (Akyürek \& Afacan, 2018). Furthermore, the students' inability to review literature affects them in the decision-making process (Akyürek \& Afacan, 2018). Another study conducted in Bangladesh indicates that students do not have adequate knowledge on conducting research 
(Matin \& Khan, 2017). Furthermore, it also states that failure to keep pace with the research plan leads to anxiety, frustration and depression during the research period. In another study on students reading for a Master of Education in Sri Lanka, it was found that students lack the ability to state the research problem and research title with clarity, they use vague terms in writing the research dissertation and their research objectives have little relevance to the suggested research topic and in moving beyond the scope of the study (Lekamge, 2018). As such, students' academic skills, understanding of the research culture and how to conduct research also appear to have an impact on their completion or non-completion of dissertations.

Some of the institutional factors that affect student completion of a dissertation are the availability of cooperation, guidance, funds and physical facilities to the students (Safari et al., 2015). Factors related to the research supervisor, who also represents the institution, include the nature of the student-supervisor relationship, supervisor's knowledge and interest in the area of study, regular contact between student and supervisor as well as provision of timely feedback (Yousefi et al., 2015). Matin \& Khan (2017) state that students not having adequate discussions with supervisors on a regular basis can affect their completion of postgraduate research. Apart from this, the research environment, peer support and facilities available are some of the other environmental factors that affect postgraduate students' completion of research studies (Matin \& Khan, 2017). Thus, it is evident that both the availability/non-availability of an environment conducive for research and the extent to which students effectively use the available resources affect their completion of postgraduate research studies. Different strategies can be adopted by students to successfully complete their postgraduate research study. These include maintaining a research diary and sharing problems arising from the research process with peers so that they can support one another (Gupta, 2012). In order to overcome difficulties while doing research, Akyürek and Afacan (2013) suggest using a brain-based learning approach.

\section{Methodology}

This study was conducted as a survey, which allowed collecting data from a large sample of students who are conducting research as part of the Master of Education Degree programme (M.Ed.) offered by the Open University of Sri Lanka (OUSL).

The main purpose of this research paper is to identify the issues encountered by students in completing the research component which is part of the Master of Education Degree programme offered by the Open University of Sri Lanka. The research component is a vital part of this study programme and is expected to broaden students' research skills in the field of education. However, our experience as members of the faculty is that the majority of students are not able to complete their research dissertation, even several years after presenting their re- 
search proposal. Therefore, the study aims at identifying personal and academic issues encountered by the students which hinder their completion of the research for the Master of Education Degree programme.

The objectives of this study are:

1) to identify the academic issues faced by the students in completing the research component, which is part of their Masters' study programme,

2) to identify the personal issues faced by the students which affect their completion of the research,

3) to make suggestions to address the issues faced by the students in completing their research.

The sample of this study consisted of students registered for the second year of the M.Ed. programme who were, at the time of data collection for the present study, engaged in the process of conducting their research as part of their programe of study. Samples of 176 students were the respondents of the survey questionnaire. All participants in this study were teachers. Of the 176 samples, 127 were females and 49 were males. A special feature of this sample is the inclusion of students representing all provinces of Sri Lanka.

For the purpose of this study, data was collected using a questionnaire consisting of 13 questions; these questions included both close-ended and open-ended questions. The items in the questionnaire required the respondents to report on their progress on the coursework component of the degree programme, provide basic details about their research, and report their progress in carrying out the study and writing of the dissertation. In addition, the items also focused on academic and personal issues faced by the students which have an impact on the completion of the dissertation and their suggestions on the support they need from the faculty in completing the research dissertation.

The questionnaire was administered during a face-to-face contact session held for the students in their second year of the M.Ed. degree programme. Two hundred and fifty students participated in this contact session and 176 returned the completed questionnaire counting a response rate of $70 \%$.

Data was analysed, both qualitatively and quantitatively, by way of identifying themes from the responses to the open-ended questionnaire items and to the close-ended items.

\section{Results and Discussion}

Results show that $81 \%$ of the respondents have completed the coursework. However, $19 \%$ have been unable to complete the coursework due to various reasons. The following graph indicates the progress of the research of those students who have completed the coursework.

Figure 1 shows that a majority of the students are still in the initial stages of their research study. Nineteen per cent (19\%) of the students who have completed their coursework are still involved in the initial stage of identifying the research problem and objectives. Twenty-two per cent (22\%) of students are in 


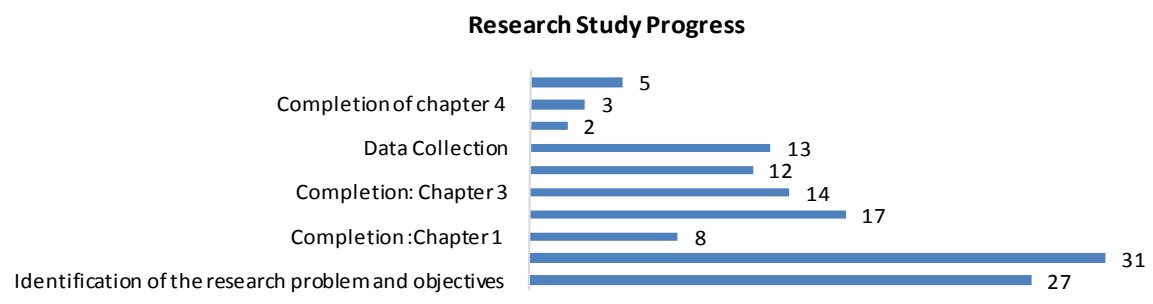

Figure 1. Research study progress of the students who have completed the coursework.

the stage of submitting the research proposal. The following graph indicates the progress of the research of the students who have not completed the coursework.

According to Figure 2, twenty-seven per cent (27\%) of the students who have not completed coursework are still in the stage of identifying the research problem and objectives. When considering the whole sample of respondents, $20 \%$ are still in that initial stage of identification of the research problem and objectives.

Though the research component is a vital part of the Master of Education Degree programme, a majority of the students have been unable to complete their research dissertation due to various reasons. The literature shows two main types of factors that affect students' completion of their postgraduate research. These are, issues pertaining to difficulties in carrying out academic activities and personal issues that impede their studies. Therefore, identifying academic issues faced by the students was one of the main objectives in the present study.

According to Figure 3, thirty-six per cent (36\%) of students out of the total number of respondents have issues in meeting supervisors. Among other issues faced by them are, the lack of library resources, difficulty in accessing information related to the proposed study from relevant institutions and the lack of literature relevant to their study. The respondents also attributed their failure to complete the dissertation to other academic issues such as difficulties in identification of a suitable area of study, the protracted time taken by the research supervisors to provide feedback during the research process, the difficulty of collecting data from several samples, the complexity of completing an action research and not being interested in the selected research topic.

The second objective of the present study was to identify personal issues faced by the students which had an impact on the completion of their research.

As indicated in Figure 4, a significant percentage has indicated workplace commitments as an issue in this regard. As mentioned previously, educational research deals with educational problems encountered by students and teachers within the classroom setting and within the school environment. However, the sample of the present study, who mainly consist of school teachers, are not able to be involved in such research activities due to their workload, which includes their regular teaching timeslots, having to perform duties as teachers in-charge of extracurricular activities and documentation. A majority indicated that they have a heavy workload in their workplaces. According to Figure 4, sixty-six per cent $(66 \%)$ of the students who completed their coursework have mentioned family commitments and school workload as a barrier to the completion of their 
Research Study Progress

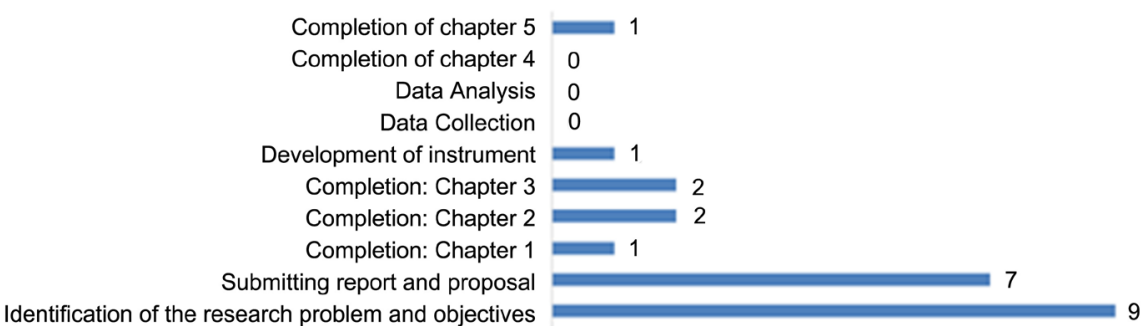

Figure 2. Research study progress of the students who have not completed the coursework.

\section{Academic Difficulties in completing the research}

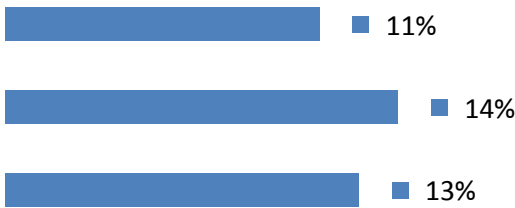

Figure 3. Academic issues faced by the students.

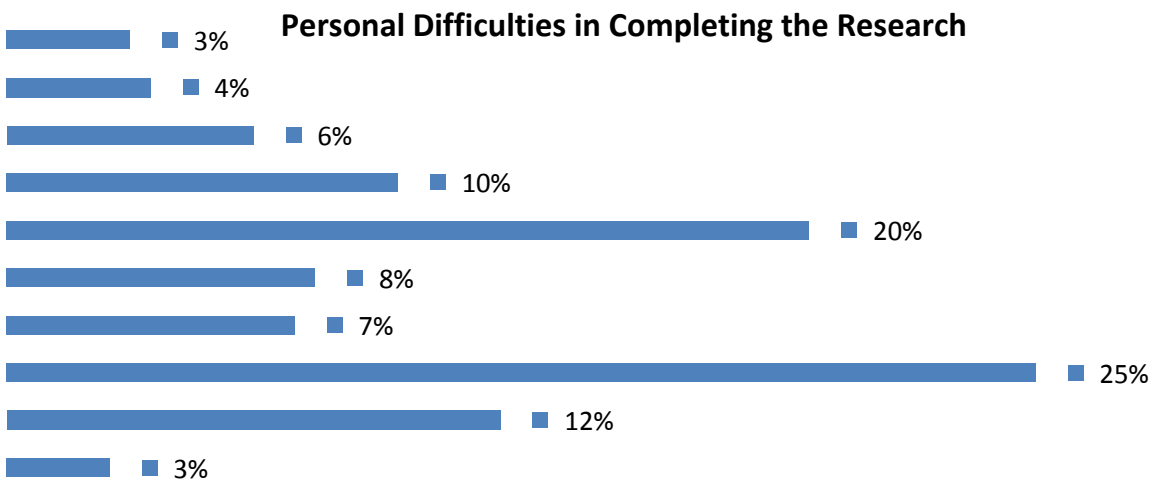

Figure 4. Personal issues faced by the students.

dissertation. In addition, they have indicated travel distance as a personal issue, a majority of them having to travel long distances to visit the Faculty. On average, a majority of the students travel about $120 \mathrm{~km}$ to reach the university; the maximum travel distance reported by respondents was $475 \mathrm{~km}$. Out of all the respondents, $20 \%$ indicated this as major problem which hinders their completion of the research. A majority indicated that they were not able to visit their research supervisor/s due to this problem.

According to the results, workplace commitments, family commitments, health problems, insufficient support from family, problems on time management and travelling long distances to university were the main personal issues. In the 
questionnaire asked from the teachers are family commitment and school workload are barriers to completion of their dissertation. They answered yes or no. according to the responses prepared in Figure 5.

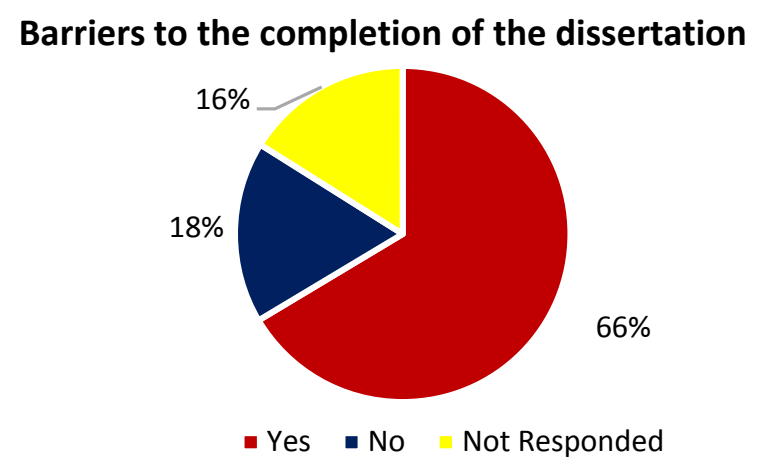

Figure 5. Family commitments and school workload as a barrier to the completion of dissertation.

\section{Conclusion/Recommendation}

Even though a research study can be considered as a systematic and scientific method to generate new knowledge to solve problems in practical applications of the teaching learning process, the present study reveals that completion of the research component is carried out by teachers and other professionals in the field of education as part of their M.Ed. Degree programme at the OUSL is hampered by a variety of personal and academic issues. Research revealed that the majority of the students did not go beyond research proposal. They also pointed out the difficulty of meeting the relevant supervisors and seeking the advices on the main educational problem. It also revealed personal problems such as living so far away from the university and having to deal with school works. Some of the recommendations that can be made to address these issues include, preparing an action plan for the students to meet the supervisors. A specific day each week can be set aside for students to meet conducting capacity building workshop for supervisors. It is necessary to organize monthly capacity building workshop to develop the research supervisory skills of the supervisors, preparing a checklist and comprehensive guidelines on writing and submission of the dissertation, and maintaining a close relationship between the supervisor and student for sustaining their motivation to overcome these issues.

\section{Conflicts of Interest}

The author declares no conflicts of interest regarding the publication of this paper.

\section{References}

Akyürek, E., \& Afacan, Ö. (2013). Effects of Brain-Based Learning Approach on Students' Motivation and Attitudes Levels in Science Class. Mevlana International Journal of Education (MIJE), 3, 104-119. https://doi.org/10.13054/mije.13.08.3.1 
Akyürek, E., \& Afacan, Ö. (2018). Problems Encountered during the Scientific Research Process in Graduate Education: The Institute of Educational Sciences. Higher Education Studies, 8, 47. https://doi.org/10.5539/hes.v8n2p47

Alam, F. (2013). A Pilot Study on Postgraduate Supervision. Procedia Engineering, 56, 875-881. https://www.sciencedirect.com/science/article/pii/S187770581300564X https://doi.org/10.1016/j.proeng.2013.03.210

Bocar, A. C. (2013). Difficulties Encountered by the Student Researchers and the Effects on Their Research Output. SSRN Electronic Journal, 1-7. https://www.researchgate.net/publication/255967042_Difficulties_Encountered_by_the _Student_-_Researchers_and_the_Effects_on_Their_Research_Output

Boykin, L. (1972). Why Research in Education? http://www.ascd.org/ASCD/pdf/journals/ed_lead/el_197204_boykin.pdf

Forbes, D. (2015). C. Mutch: Doing Educational Research: A Practitioner's Guide to Getting Started, 2nd Edition NZCER Press, Wellington, NZ, 2013. New Zealand Journal of Educational Studies, 50, 307-309. https://doi.org/10.1007/s40841-015-0032-x https://www.researchgate.net/publication/284019173_C_Mutch_Doing_Educational_R esearch_A_Practitioner's_Guide_to_Getting_Started_2nd_edition

Gupta, M. (2012). Problems Faced by Students during Post-Graduation Programme. 13th National Conference, Problems Faced by Students during Post Graduation Programme.

http://pioneerjournal.in/conferences/mapping-for-excellence/13th-national-confernce/ 3736-problems-faced-by-students-during-post-graduation-programme.html

Lekamge, D. (2018). Common Problems in Proposal Writing: Experience of Master of Education Students. Open University International Research Sessions, Colombo, 29-30 November 2018, 24-25.

Matin, M. A., \& Khan, M. (2017). Common Problems Faced by Postgraduate Students during Their Thesis Works in Bangladesh. Bangladesh Journal of Medical Education, 8 , 22-27. https://doi.org/10.3329/bjme.v8i1.32245

Qasem, F. A., \& Zayid, E. (2019). The Challenges and Problems Faced by Students in the Early Stage of Writing Research Projects in L2, University of Bisha, Saudi Arabia. European Journal of Special Education Research, 4, 32-47.

Safari, Y., Navazeshkhah, F., Azizi, M., Ziaei, M., \& Sharafi, K. (2015). The Effective Factors on the Postgraduate Students' Interest and Participation in Performing Research Activities-Case Study: Kermanshah University of Medical Science. Future Medical Education Journal, 5, 3-9. http://fmej.mums.ac.ir/article_4454.html

Wright, T. (2003). Post-Graduate Research Students: People in Context? British Journal of Guidance \& Counselling, 31, 209-227. https://doi.org/10.1080/0306988031000102379

Yousefi, A., Bazrafkan, L., \& Yamani, N. (2015). Qualitative Inquiry into the Challenges and Complexities of Research Supervision: Viewpoints of Postgraduate Students and Faculty Members. Journal of Advances in Medical Education \& Professionalism, 3, 91-98. https://www.ncbi.nlm.nih.gov/pmc/articles/PMC4530006 